\title{
Test yourself: index finger subungual pain
}

\author{
Michael C. Forney ${ }^{1}$ - Akash Garg ${ }^{1}$ • Vadim Khachaturov ${ }^{2}$ Avishkar Sharma ${ }^{3}$. \\ Murali Sundaram ${ }^{1}$
}

Published online: 2 September 2016

(C) ISS 2016

\section{Question}

36-year-old female with persistent right index finger pain Figs. 1, 2, 3, 4, 5, 6 and 7.

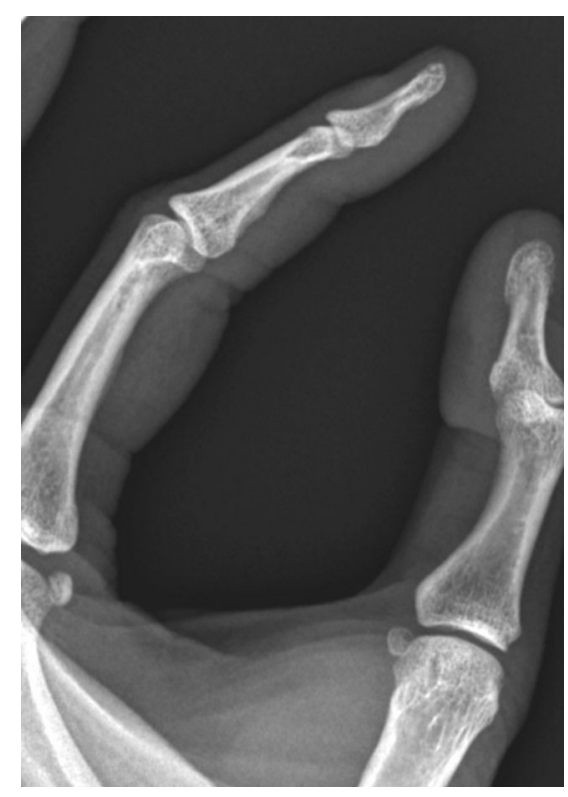

Fig. 1 Lateral radiograph of the right index finger

The diagnosis can be found at doi: 10.1007/s00256-016-2468-6

Michael C. Forney

forneym@ccf.org

Akash Garg

garga@ccf.org

Vadim Khachaturov

KHACHAV@ccf.org

Avishkar Sharma

avsharma@mcw.edu

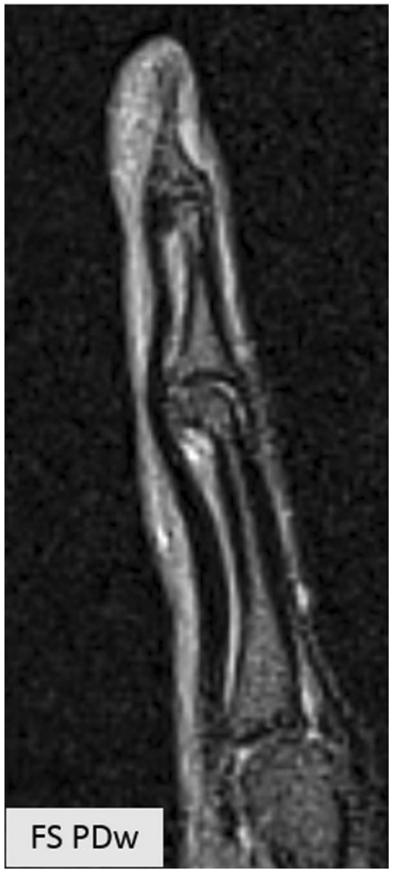

Fig. 2 Saggital fat-supressed proton density-weighted image of the right index finger
Murali Sundaram
sundarm@ccf.org

1 Imaging Institute - Section of Musculoskeletal Imaging, Cleveland Clinic, Mail Code: A21, 9500 Euclid Avenue, Cleveland, OH 44195, USA

2 Department of Pathology \& Laboratory Medicine, Cleveland Clinic, Mail Code: L21, 9500 Euclid Avenue, Cleveland, OH 44195, USA

3 Medical College of Wisconsin, 1831 N. 54th Street, Milwaukee, WI 53208, USA 


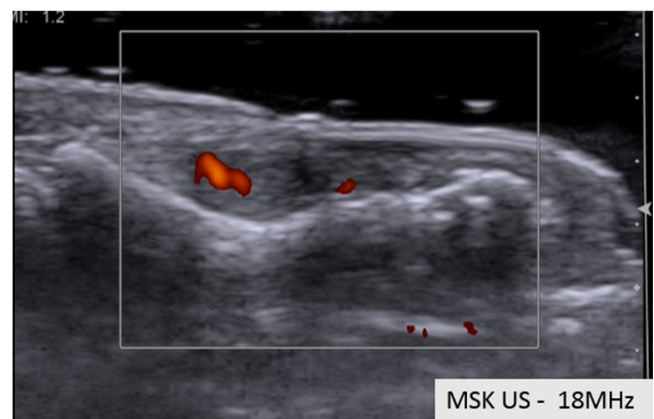

Fig. 3 Longitudinal high-frequency ultrasound image of the right index finger with power Doppler signal

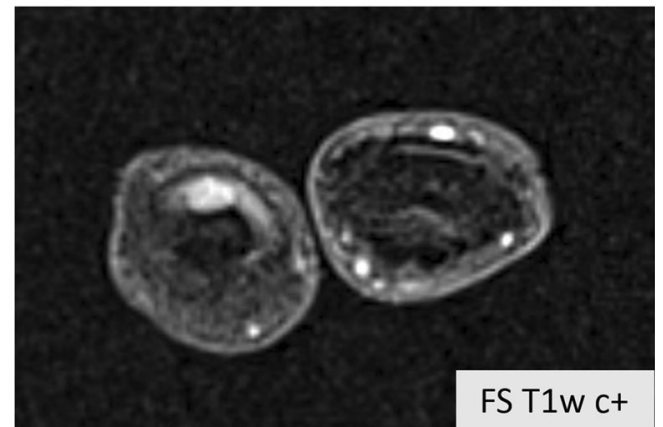

Fig. 4 Axial fat-suppressed T1-weighted postcontrast image of the right index finger

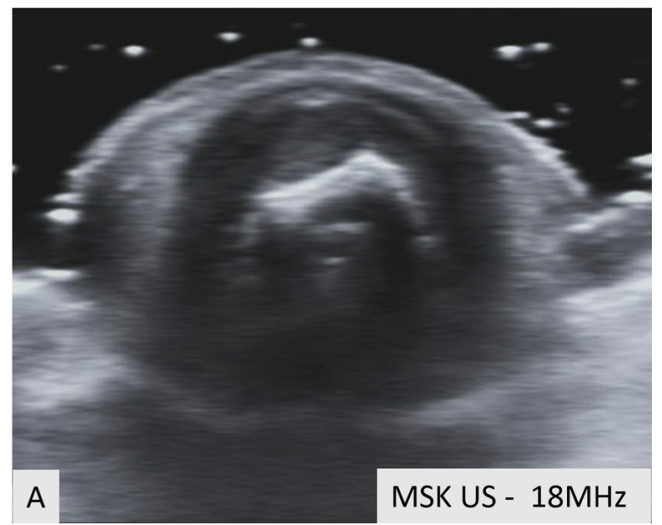

Fig. 5 Transverse high-frequency ultrasound image of the right index finger

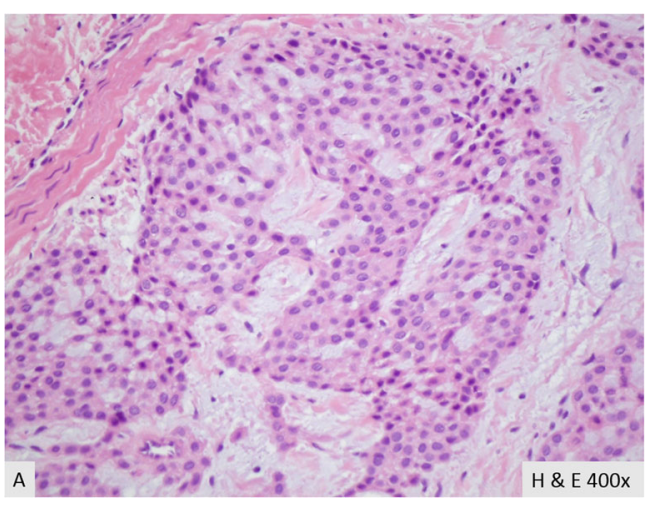

Fig. 6 High-power magnification, 400×, hematoxylin and eosin photomicrograph

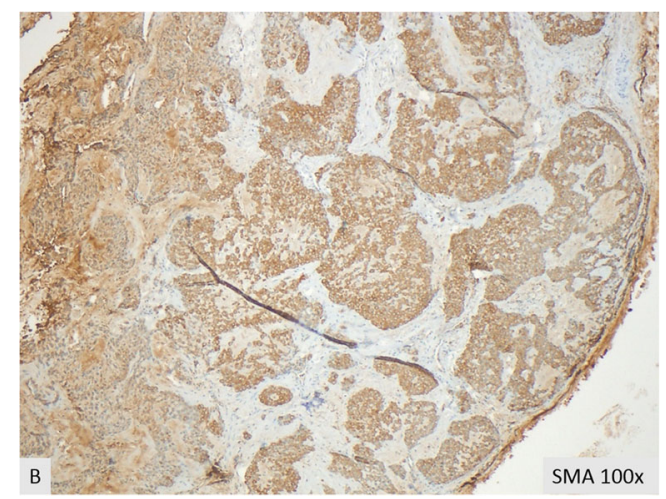

Fig. 7 Low-power magnification, $100 \times$, smooth muscle actin stain

\section{Compliance with ethical standards}

Conflict of interest The authors report no relevant conflicts of interest. 